\title{
Proteínas do feijão preto sem casca: digestibilidade em animais convencionais e isentos de germes (germ-free)
}

\author{
Proteins of dehulled black beans: digestibility in \\ conventional and germ-free animals
}

Conceição Angelina dos Santos PEREIRA ${ }^{1}$

Neuza Maria Brunoro COSTA ${ }^{1}$

\section{RE S U M O}

O feijão (Phaseolus vulgaris, L. ) é uma leguminosa de grande importância para a dieta da população brasileira. No entanto, um de seus maiores problemas é representado pelo baixo valor nutricional de suas proteínas, decorrente, por um lado, da sua baixa digestibilidade e, de outro, do teor e biodisponibilidade reduzidos de aminoácidos sulfurados. Com o objetivo de avaliar a digestibilidade das proteínas albumina e globulina do feijão preto sem casca, foram realizados ensaios biológicos com camundongos isentos de germes e convencionais e com ratos (Wistar), recém-desmamados, com idade de 21 a 25 dias. Avaliou-se ainda o Escore Químico Corrigido pela Digestibilidade da Proteína. A digestibilidade verdadeira no experimento com camundongos isentos de germes foi de 90,21 e 90,00\%, no teste com camundongos convencionais foi de 85,53 e $86,73 \%$, e no experimento com ratos foi de 82,62 e $68,53 \%$, para albumina e globulina, respectivamente. O Escore Químico Corrigido pela Digestibilidade da Proteína foi de $61,00 \%$ para a albumina e $51,00 \%$ para a globulina. A digestibilidade determinada em animais isentos de germes foi superior aos valores encontrados em animais convencionais, sugerindo que a flora intestinal esteja contribuindo para elevar o teor de nitrogênio nas fezes dos animais convencionais, e, portanto, esteja sendo subestimada a digestibilidade verdadeira do feijão.

Termos de indexação: proteínas, leguminosas, digestibilidade, animais, feijão.

\section{A B S T R A C T}

The bean (Phaseolus vulgaris, L.) is a legume of great importance in the Brazilian typical diet. Nevertheless, it presents a low protein quality due to its poor digestibility and low levels and bioavailability of its sulfur amino

\footnotetext{
1 Departamento de Nutrição e Saúde, Universidade Federal de Viçosa. Av. PH. Rolfs, s/n., 36571-000, Viçosa, MG, Brasil. Correspondência para/Correspondence to: C.A.S. PEREIRA. E-mail: casantos@mail.ufv.br
} 
acids. The aim of this study was to evaluate the digestibility of albumin and globulin protein fractions of dehulled black beans in conventional and germ-free mice and also in weaning rats (Wistar) of 21 to 25 days of age. Protein Digestibility Corrected Amino Acid Score was also determined. True digestibility values in germ-free mice were 90.21 and $90.00 \%$, in conventional mice were 85.53 and $86.73 \%$, and in rats were 82.62 and $68.53 \%$, for albumin and globulin respectively. Protein Digestibility Corrected Amino Acid Score was $61.00 \%$ for albumin and $51.00 \%$ for globulin. True digestibility values in germ-free mice were higher than those obtained with conventional animals. This fact suggests that intestinal flora is contributing to increase fecal nitrogen output in conventional animals, and, therefore, true digestibility of beans is being underestimated.

Index terms: proteins, legumes, digestibility, animals, beans.

\section{N T R O D U ÇÃ O}

O feijão comum (Phaseolus vulgaris, L.) é uma das leguminosas mais consumidas tanto no Brasil como em outros países da América do Sul (Antunes \& Sgarbieri, 1980). Como alimento, representa importante fonte de nutrientes, como proteínas, carboidratos complexos, vitaminas, minerais e fibras (Coelho, 1991; Barampama \& Simard, 1994; Geil \& Anderson, 1994). No entanto, apresenta limitações que impossibilitam a utilização de todo o seu potencial nutritivo pelo organismo (Rodriguez, 1995).

Um dos maiores problemas do feijão é representado pelo baixo valor nutricional de suas proteínas, decorrente, por um lado, da sua baixa digestibilidade e, de outro, do teor e biodisponibilidade reduzidos de aminoácidos sulfurados (Evans \& Bauer, 1978; Antunes \& Sgarbieri, 1980; Fukuda et al., 1982).

Um dos fatores a interferirem na baixa digestibilidade das proteínas do feijão cru é a presença dos inibidores de proteases. Embora estes pareçam ser geralmente inativados durante o cozimento, há relatos na literatura de atividade residual após o processamento desta leguminosa (Eicher \& Satterlee, 1988).

Bressani (1993) apontou ser multicausal a reduzida digestibilidade das proteínas do feijão e de outras leguminosas, havendo, além dos inibidores de proteases, outros fatores ligados à casca (taninos), aos cotilédones (proteínas, taninos e fitatos), ao processamento e ao armazenamento. O tanino faz parte de um grupo heterogêneo de compostos fenólicos presentes nos vegetais e pode interagir com as proteínas, formando complexos. Esta interação poderá ocorrer tanto com as proteínas dos alimentos, como com as enzimas do trato gastrintestinal (Coelho \& Lajolo, 1993). Os taninos, em quase sua totalidade, encontram-se na casca dos grãos, principalmente no feijão de cor (Coelho, 1991). O ácido fítico também pode formar complexos com proteínas e diminuir, assim, a digestibilidade deste nutriente (Torre et al., 1991).

Feijão armazenado em ambiente de alta umidade, passando por longo tempo de cocção por causa do endurecimento pós-colheita, apresenta redução do valor nutricional (Antunes $\&$ Sgarbieri, 1979). Além disso, as suas proteínas apresentam estrutura compacta, quando no estado nativo, o que as tornam resistentes à digestão (Nielsen, 1991).

Acrescenta-se às limitações mencionadas que a adição de feijão a outros alimentos é capaz de reduzir a digestibilidade total desta dieta mista em humanos (Calloway \& Kretsch, 1978).

Um melhor conhecimento das causas da baixa digestibilidade das proteínas das leguminosas pode contribuir significativamente para sua melhor utilização (Fukuda et al., 1982). Acredita-se poder haver, com a retirada da casca, um aumento da propriedade de digestão das 
proteínas do feijão pela eliminação de alguns fatores antinutricionais, como os taninos. 0 isolamento das frações protéicas poderia permitir a verificação do grau de influência de complexantes de proteínas na sua digestibilidade.

Este trabalho teve como objetivo determinar a digestibilidade das frações protéicas do feijão preto sem casca e avaliar a interferência da flora intestinal na mesma.

\section{MATERIAL E MÉTODOS}

Utilizou-se feijão preto (Phaseolus vulgaris, L.), adquirido no comércio de Belo Horizonte, MG.

O feijão foi passado em máquina de descascar arroz, para quebrar os grãos, e, em seguida, foi imerso em álcool etílico hidratado $\left(92,8^{\circ}\right)$ por uma hora, sendo descascado manualmente. Procedeu-se à moagem em moinho de facas, utilizando peneiras de 20 mesh e, posteriormente, procedeu-se à extração das frações protéicas. Este procedimento foi feito agitando-se, durante $24 \mathrm{~h}$, sob refrigeração $\left(10^{\circ} \mathrm{C}\right), 100 \mathrm{~g}$ de farinha de feijão sem casca, em $1000 \mathrm{~mL}$ de água destilada contendo $16,9 \mathrm{~g}$ de $\mathrm{NaCl}$ e $0,02 \%$ de azida sódica. A suspensão foi, então, centrifugada (750 g/15min). O precipitado foi descartado e o sobrenadante, utilizado para obtenção das frações protéicas, foi dialisado por $24 \mathrm{~h}$, por duas vezes consecutivas, contra água destilada, e, a seguir, por mais $24 \mathrm{~h}$, contra água deionizada, em câmara fria $\left(10^{\circ} \mathrm{C}\right)$, de forma a precipitar as globulinas (Rodriguez, 1995), que foram separadas por centrifugação e congeladas para posterior liofilização. As albuminas foram submetidas à pervaporação (evaporação da água utilizando ar quente) e posteriormente à liofilização. O sobrenadante obtido após a primeira centrifugação foi aquecido a $80^{\circ} \mathrm{C}$ em banho-maria, por 30 minutos, para inativação dos fatores antinutricionais, segundo metodologia proposta por Rodriguez (1995). Foi determinado o teor de nitrogênio da albumina e globulina pelo método semimicro Kjeldahl, usando-se o fator de conversão de 6,25 para a obtenção do teor protéico (Association of Official..., 1975).

Foram realizados três ensaios de digestibilidade in vivo. O primeiro com camundongos isentos de germes, o segundo com camundongos convencionais e o terceiro com ratos Wistar.

Para o teste com camundongos, foram preparadas uma ração aprotéica e outras três rações cujas fontes protéicas foram: albumina, globulina e caseína como padrão. Adicionou-se água às dietas, na proporção de 1 : 1 (PN). As rações foram esterilizadas a $120^{\circ} \mathrm{C}$, por $40 \mathrm{~min}$.

No experimento com ratos, foram preparadas uma ração aprotéica e quatro rações cujas fontes protéicas foram: albumina, globulina, feijão sem casca e caseína como padrão. No preparo da ração à base de feijão sem casca, este sofreu cocção com água na proporção de $1: 1,5$ (feijão : água), em autoclave a $105^{\circ} \mathrm{C}$, por $30 \mathrm{~min}$. O feijão autoclavado foi seco em estufa com circulação de ar, a $60^{\circ} \mathrm{C}$, por $15 \mathrm{~h}$ e, em seguida, moído em moinho de facas.

\section{Ensaios biológicos}

\section{Ensaio com camundongos isentos de germes}

Utilizaram-se neste ensaio 24 camundongos, machos, isentos de germes, raça Suíço NIH, recém-desmamados, com peso inicial variando de 7 a $10 \mathrm{~g}$. Estes animais foram criados no Laboratório de Gnotobiologia e Nutrição da Universidade Federal de Minas Gerais a partir de matrizes obtidas da Taconic (USA). Eles foram divididos em quatro grupos de seis e mantidos em isoladores de plástico flexível (Class Biological (lean, USA), em gaiolas individuais aramadas, onde receberam água e alimento ad libitum. Os grupos experimentais foram: dieta aprotéica, dieta de caseína, dieta de albumina e dieta de globulina (Tabela 1). O experimento foi conduzido por 10 dias (Durigan et al., 1987). 


\section{Ensaio com camundongos convencionais}

Utilizaram-se neste experimento 24 camundongos convencionais, machos, raça Suíço $\mathrm{NIH}$, com peso inicial variando de 7 a $10 \mathrm{~g}$. Os animais foram divididos em quatro grupos de seis e mantidos em gaiolas individuais aramadas, onde receberam água e alimento ad libitum. O tempo de duração da experiência e os grupos foram os mesmos do ensaio com camundongos isentos de germes (Tabela 1).

\section{Ensaio com ratos}

Utilizaram-se 30 ratos machos, linhagem Wistar, recém-desmamados, com média de 23 dias de idade e com peso variando de 50 a $60 \mathrm{~g}$. Os animais foram divididos em cinco grupos com seis ratos cada, de modo que a diferença dos pesos médios entre os grupos não excedesse $5 \mathrm{~g}$, conforme recomendação da Association of Official... (1975), sendo os mesmos distribuídos em gaiolas individuais aramadas, onde receberam

Tabela 1. Composição das dietas experimentais utilizadas no experimento com camundongos isentos de germes e convencionais ( $\mathrm{g} / 100 \mathrm{~g}$ ).

\begin{tabular}{|c|c|c|c|c|}
\hline \multirow{2}{*}{ Ingredientes } & \multicolumn{4}{|c|}{ Dietas } \\
\hline & DA & DG & DC & DLN \\
\hline Albumina & 15,87 & - & - & - \\
\hline Globulina & - & 12,86 & - & - \\
\hline Caseína & - & - & 12,44 & - \\
\hline Mistura salina $\left({ }^{*}\right)$ & 3,50 & 3,50 & 3,50 & 3,50 \\
\hline Mistura vitamínica $\left({ }^{* *}\right)$ & 10,00 & 10,00 & 10,00 & 10,00 \\
\hline Óleo de soja & 5,00 & 5,00 & 5,00 & 5,00 \\
\hline Cloreto de colina & 0,20 & 0,20 & 0,20 & 0,20 \\
\hline Amido de milho & 74,43 & 77,44 & 77,86 & 90,30 \\
\hline \% de proteína & 10,00 & 9,57 & 9,77 & nd \\
\hline Energia Kcal & 406,20 & 406,20 & 406,20 & 406,20 \\
\hline
\end{tabular}

Tabela 2. Composição das dietas experimentais utilizadas no experimento com ratos ( $\mathrm{g} / 100 \mathrm{~g}$ de mistura).

\begin{tabular}{lccccc}
\hline Ingredientes & \multicolumn{4}{c}{ Dietas } \\
\cline { 2 - 5 } & DA & DG & DFSC & DC & DLN \\
\hline Albumina & 15,87 & - & - & - & - \\
Globulina & - & 12,86 & - & - & - \\
Feijão sem casca & - & - & 42,62 & 12,44 & - \\
Caseína & - & - & - & 3,50 & 3,50 \\
Mistura salina $\left(^{*}\right)$ & 3,50 & 3,50 & 3,50 & 1,00 & 1,00 \\
Mistura vitamínica $\left(^{*}\right)$ & 1,00 & 1,00 & 1,00 & 5,00 & 5,00 \\
Óleo de soja & 5,00 & 5,00 & 5,00 & 0,20 & 90,30 \\
Cloreto de colina & 0,20 & 0,20 & 0,20 & 77,86 & nd \\
Amido de milho & 74,43 & 77,44 & 47,68 & 10,00 & \\
\hline \% de proteína & 10,00 & 10,03 & 10,00 & \\
\hline
\end{tabular}

(*) AIN 1977

DA = dieta de albumina; DG = dieta de globulina; DFSC = dieta de feijão sem casca; DC = dieta de caseína (padrão); DLN = dieta livre de nitrogênio (aprotéica); nd = não-determinado. 
água e alimento ad libitum. As dietas eram isoprotéicas e isocalóricas (Tabela 1). Os grupos experimentais foram: Grupo 1: dieta aprotéica; Grupo 2: dieta de caseína; Grupo 3: dieta de albumina; Grupo 4: dieta de globulina; Grupo 5: dieta de feijão sem casca (Tabela 2). O experimento foi conduzido durante 10 dias, e o controle do peso foi feito no $1^{\circ}$ e no $10^{\circ}$ dia (Angelis et al., 1982; Durigan et al., 1987).

\section{Determinação da digestibilidade in vivo}

Para a determinação da digestibilidade, as dietas foram marcadas com indigocarmin, na proporção de 200 mg/ 100 g, e foram oferecidas aos animais no $3^{\circ}$ e no $9^{\circ}$ dia, nos três ensaios realizados.

As fezes foram coletadas do $4^{\circ}$ ao $10^{\circ}$ dia, em recipiente individual, e mantidas sob refrigeração, no caso dos camundongos convencionais e ratos; no caso dos camundongos isentos de germes, elas foram retiradas dos isoladores somente no final do experimento.

Ao término da experiência, as fezes foram secas em estufa com circulação de ar a $105^{\circ} \mathrm{C}$, por $24 \mathrm{~h}$. Foram resfriadas, pesadas e trituradas em multiprocessador para determinação do teor de nitrogênio.

A digestibilidade verdadeira foi calculada, medindo-se a quantidade de nitrogênio ingerida na dieta, a quantia excretada nas fezes e a perda metabólica no material fecal. Esta última foi estimada pelo montante de nitrogênio excretado pelos ratos alimentados com a dieta livre desta substância (Amaya et al., 1991).

\section{Determinação do escore químico corrigido pela digestibilidade da proteína (PDCAAS)}

Calculou-se Escore Químico Corrigido pela Digestibilidade da Proteína pela equação:

PDCAAS = escore mais baixo do aminoácido essencial x digestibilidade da proteína.
A proteína cujo PDCCAS for igual ou superior a 1,0 é considerada de boa qualidade (Henley \& Kurster, 1994).

Para se obter o perfil aminoacídico, a albumina e a globulina foram submetidas a três hidrólises distintas, sendo uma ácida, uma básica, e uma terceira onde foi feita uma oxidação com ácido perfórmico, para a recuperação da metionina e da cisteína. Posteriormente, as amostras hidrolisadas foram evaporadas e rediluídas em ácido. Em seguida, elas foram filtradas e injetadas em aparelho previamente calibrado com padrão externo. O aparelho utilizado foi o Amino Acid Analyzer, modelo Hitachi L-8500 A, exclusivo para análises de aminoácidos.

\section{Análise estatística}

Procedeu-se à análise de variância (ANOVA), para determinação do valor de " $F$ ". Para " $F$ " significativo, utilizou-se o teste de Tukey, a $5 \%$ de probabilidade, para comparação entre as médias. A dispersão da média foi expressa nas tabelas de resultados, como desvio-padrão da média.

\section{RESULTADOSE DISCUSSÃO}

O teor de proteína encontrado, para o feijão preto sem casca, foi de 19,7\% (Tabela 3), inferior ao valor de $22,17 \%$ obtido por Rosa (1996) com a mesma leguminosa. Esta variação pode ser decorrente da diferença entre os cultivares estudados, da diferença nas condições de plantio e/ou de armazenamento ou da variabilidade ao se descascar o feijão manualmente. Este teor difere também dos $22,0 \%$ encontrados por Varriano-Marston \& Omana (1979) no feijão preto com casca e dos 22,9\% obtidos por Hernandez et al. (1984) com o feijão preto cru. Já Durigan et al. (1987) encontraram para o feijão preto cru, variedade Rico $23,24,5 \%$, e para o tipo Iguaçu, $27,2 \%$. 
Bressani et al. (1981) obtiveram resultados que variaram de 19,2 a 25,9\%, para cinco espécies desta mesma leguminosa. Observa-se, portanto, a existência de variação no teor protéico entre feijão inteiro e sem casca.

O grau de extração das frações protéicas, utilizando $\mathrm{NaCl}$ 0,2 M, foi de 41,7 e 58,3\%, respectivamente, para a albumina e a globulina, em relação ao total de proteína do feijão preto sem casca. Marquez e Lajolo (1981) apresentaram um rendimento de 31,5 e 51,9\%, respectivamente, para a albumina e a globulina extraídas do feijão variedade Carioca, enquanto Chang \& Satterlee (1981) identificaram no feijão Great Northern 43,3 e 56,7\%, respectivamente. Verifica-se que, quando se utiliza $\mathrm{NaCl} 0,2 \mathrm{M}$, obtém-se melhor grau de extração, tanto da albumina quanto da globulina.

Segundo Rodriguez (1995), a concentração de cada fração protéica e sua composição polipeptídica dependem da forma de extração, pois, utilizando diferentes soluções extratoras, conseguem-se rendimentos distintos.

Os teores protéicos encontrados nas frações de albumina e globulina foram de 59,80 e $73,80 \%$, respectivamente. Segundo Bhatty (1982), a albumina de feijão contém de 9,50 a $12,40 \%$ de nitrogênio, o que corresponde de 59,40 a $77,50 \%$ de proteína, utilizando para cálculo do teor protéico o valor de nitrogênio multiplicado por 6,25.

O valor obtido no experimento para a digestibilidade verdadeira do feijão preto sem casca foi de $77,0 \%$, portanto, próximo ao encontrado por Sgarbieri \& Whitaker (1982), o qual foi de 76,8\% (Tabela 3).

Wu et al. (1995), ao submeterem o feijão vermelho kidney beans a nove tratamentos térmicos, identificaram valores de digestibilidade aparente e verdadeira entre 67,9 e 78,8\% e entre 72,6 e $82,1 \%$, respectivamente. Com a variedade Rosinha G2, Sgarbieri \& Whitaker (1982) encontraram marcantes diferenças na digestibilidade entre a proteína total da farinha integral (59,0\%), a proteína total isolada (73,0\%), a fração albumínica $(72,0 \%)$ e a fração globulínica $(83,0 \%)$. Estas preparações foram autoclavadas a $121^{\circ} \mathrm{C}$, por $15 \mathrm{~min}$, antes do preparo das dietas dos ratos.

Eicher \& Satterlee (1988) obtiveram um resultado de $20,8 \%$ para a digestibilidade aparente do feijão cru. Sgarbieri \& Whitaker (1982) acrescentam ser baixo o valor biológico das proteínas do feijão, quando comparado com o de outros alimentos.

Quando Fukuda et al. (1982) determinaram a digestibilidade aparente do feijão preto cozido, os valores encontrados variaram entre 65,6 e $66,7 \%$. Segundo estes autores, a cocção do feijão não somente produz a destruição e a inativação de fatores antinutricionais, mas também afeta a estrutura da proteína, tornando-a mais digerível. Sathe \& Salunkle (1981) acrescentam que o calor úmido melhora a digestibilidade das proteínas do feijão em relação ao calor seco.

Amaya et al. (1991) estudaram o feijão preto submetido à recocção, a cada $12 \mathrm{~h}$, à

Tabela 3. Digestibilidade verdadeira (DV) da dieta de caseína, albumina e globulina em camundongos isentos de germes e convencioanis e ratos (média e desvio-padrão).

\begin{tabular}{lccc}
\hline \multirow{2}{*}{ Dieta } & & $\begin{array}{c}\text { DV \% } \\
\text { Camundongos }\end{array}$ & \\
\cline { 2 - 4 } & Isentos de germes* $^{*}$ & Convencionais $^{*}$ & Ratos $^{* *}$ \\
\hline Caseína & $90,78 \pm 0,85$ & $87,53 \pm 0,69$ & $96,14 \pm 0,26 \mathrm{a}$ \\
Albumina & $90,21 \pm 1,42$ & $85,53 \pm 0,25$ & $82,62 \pm 1,56 \mathrm{~b}$ \\
Globulina & $90,00 \pm 1,91$ & $86,73 \pm 1,48$ & $68,53 \pm 3,33 \mathrm{c}$ \\
FPSC & & & $77,59 \pm 0,33 \mathrm{~b}$ \\
\hline
\end{tabular}

(*) As médias não diferem estatisticamente entre $\mathrm{si}(\mathrm{p}>0,05)$.

${ }^{* *}$ As médias seguidas da mesma letra na coluna não diferem estatisticamente entre si, pelo teste de Tukey $(p>0,05)$. 
temperatura de ebulição do caldo $\left(96^{\circ} \mathrm{C}\right)$, durante $15 \mathrm{~min}$. Este experimento teve como resultado valores de digestibilidade aparente e verdadeira variando de 66 a $89 \%$ e de 68 a $91 \%$.

Hernandez et al. (1984) encontraram um percentual de $62,8 \%$ para a digestibilidade aparente do feijão preto e de $58,4 \%$ para a digestibilidade in vitro. Bressani (1989) obteve taxas de 49,6 a 54,6\% para a digestibilidade aparente deste mesmo produto em humanos.

Deshpande \& Nielsen (1987) relatam ocorrer uma drástica redução da digestibilidade da albumina do feijão, quando submetida ao calor. Contradizendo este relato, a digestibilidade verdadeira da albumina $(82,62 \%)$ foi superior à da globulina (68,53\%), nesta pesquisa (Tabela 3).

Segundo Bressani (1989), os valores de digestibilidade in vivo são mais altos que os da digestibilidade in vitro. De acordo com Carias et al. (1995), a digestibilidade verdadeira é sempre maior que a aparente, isto porque esta última não considera as perdas obrigatórias de nitrogênio nas fezes.

A digestibilidade é o primeiro fator a afetar a eficiência da utilização protéica da dieta. Quando certas ligações peptídicas não são hidrolisadas no processo digestivo, parte da proteína é excretada nas fezes ou transformada em produtos do metabolismo pelos microorganismos do intestino grosso (Sgarbieri \& Whitaker, 1982). Boonvisut \& Whitaker (1976) acrescentam que a estrutura terciária da proteína afeta a digestibilidade e pode não ser facilmente destruída pelo tratamento térmico. Registram, ainda, que o inibidor da enzima proteolítica do feijão é conhecido por conter ligações dissulfídricas, as quais contribuem para a estabilização da estrutura terciária da proteína.

A melhoria da capacidade de digestão não implica necessariamente o aumento da qualidade protéica, pois os aminoácidos podem estar sendo bem absorvidos, mas podem não estar participando da síntese protéica em virtude da deficiência de alguns aminoácidos essenciais.

De acordo com Bressani (1989), o tegumento do feijão preto é rico em taninos, os quais interferem no processo digestivo, por interação com a proteína ingerida ou com as enzimas digestivas presentes no trato gastrintestinal. Portanto, é de se esperar a digestibilidade e qualidade protéica mais elevadas e o menor conteúdo de taninos no feijão descascado e cozido. Segundo o mesmo autor, a digestibilidade protéica requer estudos adicionais sobre os fatores inerentes à semente e sobre o processo que a torna tão baixa. Ele sugere levar isto em consideração quando se trata de seu consumo.

Os valores de digestibilidade com camundongos isentos de germes foram superiores aos com camundongos convencionais. Estes resultados podem ser decorrentes da interferência da flora intestinal, isto é, nos camundongos convencionais parte do nitrogênio excretado nas fezes é proveniente das células microbianas, cujo crescimento é favorecido pelos nutrientes não digeridos e não absorvidos no intestino delgado, como as fibras alimentares e algumas proteínas.

Tabela 4. Composição aminoacídica da albumina e da globulina obtidas do feijão preto sem casca.

\begin{tabular}{lcc}
\hline \multirow{2}{*}{ Aminoácido } & \multicolumn{2}{c}{ mg de aminoácidos/ g de proteína } \\
\cline { 2 - 3 } & Albumina & Globulina \\
\hline Alanina & 30,41 & 27,12 \\
Ácido Aspártico & 81,22 & 90,43 \\
Ácido Glutâmico & 83,67 & 129,18 \\
Arginina & 35,14 & 45,50 \\
Fenil. + tiros & 60,23 & 77,13 \\
Glicina & 27,52 & 27,05 \\
Histidina & 18,60 & 23,58 \\
Isoleucina & 29,23 & 37,00 \\
Leucina & 52,24 & 69,71 \\
Lisina & 47,07 & 52,42 \\
Met. + cisteína & 18,87 & 130,91 \\
Prolina & 28,98 & 28,52 \\
Serina & 41,94 & 46,54 \\
Treonina & 39,21 & 25,72 \\
Triptofano & 9,45 & 57,41 \\
Valina & 38,47 & 39,35 \\
\hline & & \\
\hline
\end{tabular}


Tabela 5. PDCAAS da albumina e da globulina obtidas do feijão preto sem casca.

\begin{tabular}{|c|c|c|c|c|c|c|c|}
\hline \multirow[t]{2}{*}{$\frac{\text { I }}{\text { a.a essencial }}$} & \multicolumn{2}{|c|}{$\begin{array}{c}\text { ॥ } \\
\text { mg/g proteína }\end{array}$} & \multirow{2}{*}{$\begin{array}{c}\text { III } \\
\text { Padrão FAO/WHO } \\
2-5 \text { anos (mg/g prot) }\end{array}$} & \multicolumn{2}{|c|}{$\begin{array}{c}\text { IV } \\
\text { Escore a.a }\end{array}$} & \multicolumn{2}{|c|}{$\begin{array}{c}V \\
\text { PDCAAS }\end{array}$} \\
\hline & albumina & globulina & & albumina & globulina & albumina & globulina \\
\hline Fenil. + tiros & 60,23 & 77,13 & 63 & 0,95 & 1,22 & 0,78 & 0,83 \\
\hline Histidina & 18,60 & 23,58 & 19 & 0,97 & 1,24 & 0,80 & 0,84 \\
\hline Isoleucina & 29,23 & 37,00 & 28 & 1,04 & 1,32 & 0,85 & 0,90 \\
\hline Leucina & 52,24 & 69,71 & 66 & 0,79 & 1,05 & 0,65 & 0,70 \\
\hline Lisina & 47,07 & 52,42 & 58 & 0,81 & 0,90 & 0,66 & 0,61 \\
\hline Met. + cist & 18,72 & 130,91 & 25 & 0,74 & 5,23 & $0,61^{*}$ & 3,58 \\
\hline Treonina & 39,21 & 25,72 & 34 & 1,15 & 0,75 & 0,95 & $0,51^{*}$ \\
\hline Triptofano & 9,45 & 57,41 & 11 & 0,85 & 5,21 & 0,70 & 3,57 \\
\hline Valina & 38,47 & 39,35 & 35 & 1,09 & 1,12 & 0,90 & 0,76 \\
\hline
\end{tabular}

Escore de a.a. = coluna II/III

PDCAAS $=1^{\circ}$ aminoácido limitante (coluna IV) $\mathrm{x}$ digestibilidade verdadeira do experimento com ratos. Digestibilidade verdadeira: albumina $=82,62 \%$; globulina $=68,53 \%$.

${ }^{(*)}$ PDCAAS: albumina $=0,61$ ou $61 \%$; globulina $=0,51$ ou $51 \%$.

De acordo com os resultados obtidos, a albumina apresenta valores inferiores aos da globulina para os seguintes aminoácidos: arginina, ácido aspártico, isoleucina, leucina, ácido glutâmico, lisina, cistina, metionina, fenilalanina, tirosina, triptofano, histidina e serina. Esta maior deficiência da albumina em aminoácidos pode ter sido compensada pela sua maior digestibilidade no experimento com ratos. Observa-se, também, que a albumina e a globulina se complementam (Tabelas 4 e 5).

\section{A GRADECIMENTO}

Ao Professor Ênio Cardillo Vieira, pela orientação do experimento com animais isentos de germes, realizado no Laboratório de Gnotobiologia e Nutrição da Universidade Federal de Minas Gerais (UFMG).

\section{REFERÊ NCIAS B I B LIOGRÁFICAS}

AMAYA, H., ACEVEDO, E., BRESSANI, R. Efecto del recalientamiento sobre la disponibilidad de hierro y valor nutritivo de la proteina del frijol negro (Phaseolus vulgaris) cocido. Archivos Latinoamericanos de Nutrición, Guatemala, v.16, n.2, p.222-237, 1991.
AMERICAN INSTITUTE OF NUTRITION. Report of American Institute of Nutrition Ad Hoc Committee on Standards for Nutrition Studies. Journal of Nutrition, Bethesda, v.107, n.7, p.1340-1348, 1977.

ANGELIS, R.C., ELIAS, L.G., BRESSANI, R. Mezclas de arroz y frijol. Valor nutricional de las proteínas de las mezclas. Archivos Latinoamericanos de Nutrición, Caracas, v.32, n.1, p.47-63, 1982.

ANTUNES, P.L., SGARBIERI, V.C. Influence of time and conditions of storage on technological and nutritional properties of a dry bean (Phaseolus vulgaris, L.) variety Rosinha G2. Journal of Food Science, Chicago, v.44, n.6, p.1703-1706, 1979.

ANTUNES, P.L., SGARBIERI, V.C. Effect of heat treatment on the toxicity and nutritive value of dry bean (Phaseolus vulgaris var. Rosinha G2) proteins. Journal of Agricultural and Food Chemistry, Washington DC, v.28, p.935-938, 1980.

ASSOCIATION OF OFFICIAL AGRICULTURAL CHEMISTS. Official methods of analysis of the AOAC. 12.ed. Washington DC, 1975. 110p.

BARAMPAMA, Z., SIMARD, R.E. Oligosaccharides, antinutritional factors and protein digestibility of dry beans as affected by processing. Journal of Food Science, Chicago, v.59, n.4, p.833-838, 1994.

BHATTY, R.S. Albumin proteins of eight edible grain legume species: electrophoretic patterns and aminoacid composition. Journal of Agricultural and Food Chemistry, Washington DC, v.30, n.3, p.620-622, 1982. 
BOONVISUT, S., WHITAKER, J.R. Effect of heat, amylase and disulfide bond cleavage on the in vitro digestibility of soybean proteins. Journal of Agricultural and Food Chemistry, Washington DC, v.24, n.6, p.1130-1135, 1976.

BRESSANI, R., ELIAS, L.G., ESPANA, M.E. Posibles relaciones entre medidas fisicas, quimicas y nutricionales em frijol comum (Phaseolus vulgaris). Archivos Latinoamericanos de Nutrición, Caracas, v.31, n.3, p.550-570, 1981.

BRESSANI, R. Revisión sobre la calidad del grano de frijol. Archivos Latinoamericanos de Nutrición, Guatemala, v.39, n.3, p.419-443, 1989.

BRESSANI, R. Grain quality of common beans. Food Reviews International, v.9, p.237-297, 1993.

CALLOWAY, D.H., KRETSCH, M.J. Protein and energy utilization in men given rural Guatemalan diet and egg formulas with and without added oat bran. American Journal of Clinical Nutrition, Bethesda, v.31, n.6, p.1118-1126, 1978.

CARIAS, D., CIOCCIA, A.M., HEVIA, P. Grado de concordancia entre la digestibilidad de proteínas animales y vegetales medidas in vivo e in vitro y su efecto sobre el cómputo químico. Archivos Latinoamericanos de Nutrición, Guatemala, v.45, n.2, p.111-116, 1995.

CHANG, K.C., SATTERLEE, L.D. Isolation and characterization of the major protein from great northern bean (Phaseolus vulgaris, L.) proteins. Journal of Food Science, Chicago, v.46, n.31, p.1368-1373, 1981.

COELHO, R.G. Considerações sobre as proteínas do feijão. Revista de Nutrição da PUCCAMP, Campinas, v.4, n. 1/2, p.122-145, 1991.

COELHO, J.V., LAJOLO, F.M. Evolução dos fenólicos totais e taninos condensados (protoantocianidinas) durante o desenvolvimento das sementes do feijão (Phaseolus vulgaris, L.). Archivos Latinoamericanos de Nutrición, Guatemala, v.43, n.1, p.61-65, 1993.

DESHPANDE, S.S., NIELSEN, S.S. In vitro enzymatic hydrolysis of phaseolin, the major storage protein of Phaseolus vulgaris, L. Journal of Food Science, Chicago, v.52, p.1330-1334, 1987.
DURIGAN, J.F., SGARBIERI, V.C., BULISANI, E.A. Protein value of dry bean Cultivars: factors interfering with biological utilization. Journal of Agricultural and Food Chemistry, Washington DC, v.35, p.694-698, 1987.

EICHER, N.J., SATTERLEE, L.D. Nutritional quality of Great Northern bean proteins processed at varying pH. Journal of Food Science, Chicago, v.53, n.4, p.1139-1143, 1988.

EVANS, R.J., BAUER, D.H. Studies of the poor utilization by the rat of methionine and cystine in heated dry bean seed (Phaseolus vulgaris). Journal of Agricultural and Food Chemistry, Washington DC, v.26, n.4, p.779-784, 1978.

FUKUDA, G., ELIAS, L.G., BRESSANI, R. Significado de algunos factores antifisiologicos y nutricionales em la evaluación biológica de diferentes cultivares de frijol comum (Phaseolus vulgaris). Archivos Latinoamericanos de Nutrición, Caracas, v.32, n.4, p.945-960, 1982.

GEIL, P.B., ANDERSON, J.W. Nutrition and health implications of dry beans: a review. American Journal of Clinical Nutrition, Bethesda, v.13, n.6, p.549-558, 1994.

HENLEY, E.C., KUSTER, J.M. Protein quality evaluation by protein digestibility-corrected amino acid scoring. Food Technology, Chicago, v.4, p.74-77, 1994.

HERNANDEZ, M., La VeJA, A., SOTElo, A. Determinacion de la digestibilidad proteinica in vitro e in vivo em cereales y leguminosas, crudos y cocidos. Archivos Latinoamericanos de Nutrición, Caracas, v.34, n.3, p.514-522, 1984.

MARQUEZ, V.M.L., LAJOLO, F.M. Composition and digestibility of albumin, globulins and glutelins from Phaseolus vulgaris. Journal of Agricultural and Food Chemistry, Washington DC, v.29, n.8, p.1068-1074, 1981

NIELSEN, S.S. Digestibility of legume protein. Food Technology, Chicago, v.45, n.6, p.112-114, 1991.

RODRIGUEZ, M.I.G. Digestibilidade e biodisponibilidade de metionina de frações protéicas do 
feijão (Phaseolus vulgaris): estudo in vitro. São Paulo, 1995. 115p.Tese (Doutorado em Ciência dos Alimentos) - Universidade de São Paulo, 1995.

ROSA, C.O.B. Propriedade do feijão (Phaseolus vulgaris, L.) na redução do colesterol sanguíneo em ratos hipercolesterôlemicos. Viçosa, 1996. 80p. Dissertação (Mestrado em Ciência e Tecnologia de Alimentos) - Universidade Federal de Viçosa, 1996.

SATHE, S.K., SALUNKLE, D.K. Solubilization and electrophoretic characterization of the Great Northern bean (Phaseolus vulgaris, L.) proteins. Journal of Food Science, Chicago, v.46, n.25, p.82-87, 1981.

SGARBIERI, V.C., WHITAKER, J.R. Physical, chemical and nutritional properties of common beans (Phaseolus) proteins. Advances Food Research, v.28, n.3, p.93-166, 1982.
TORRE, M., RODRIGUES, A.R., SAURA-CALIXTO, F. Effects of dietary fiber and phytic acid on mineral bioavailability. Critical Reviews Food Science Nutrition, v.1, n.1, p.1-22, 1991.

VARRIANO-MARSTON, E., OMANA, E. Effects of sodium salt solutions on the chemical composition and morphology of black beans (Phaseolus vulgaris). Journal of Food Science, Chicago, v.44, n.2, p.531-536, 1979.

WU, W., WILLIANS, W.P., KUNKEL, M.E., ACTON, J.C., HUANG, Y., WARDLAW, F.B., GRIMES, L.W. True protein digestibility and digestibility corrected amino acid score of red kidney beans (Phaseolus vulgaris, L.) Journal of Agricultural and Food Chemistry, Washington DC, v.43, n.5, p.1295-1298, 1995.

Recebido para publicação em 5 de setembro de 2000 e aceito em 30 de março de 2001. 